\title{
PRENATAL DEVELOPMENTAL TOXICITY EVALUATION OF FUROSTANOL SAPONIN GLYCOSIDE BASED STANDARDIZED FENUGREEK SEED EXTRACT DURING ORGANOGENESIS PERIOD OF PREGNANCY IN RATS
}

\author{
PALLAVI DESHPANDE ${ }^{*}$, VISHWARAMAN MOHAN1 ${ }^{1}$, MUKUL PORE ${ }^{2}$, SHAILESH GUMASTE2, \\ PRASAD THAKURDESAI ${ }^{1}$
}

1Indus Biotech Private Limited, Kondhwa, Pune, Maharashtra, 411048, India, ${ }^{2}$ Intox Pvt. Ltd., Pune, Maharashtra, 412115, India, Email: pallavi@indusbiotech.com

Received: 28 Aug 2016 Revised and Accepted: 05 Oct 2016

\begin{abstract}
Objective: To evaluate prenatal safety of furostanol saponin glycoside based standardized fenugreek seed extract (Fenu-FG) on pregnant female Wistar rats on embryo-fetal development organogenesis period in accordance with OECD guideline (No. 414).

Methods: Fenu-FG was administered to pregnant rats by gavage at 250, 500, and $1000 \mathrm{mg} / \mathrm{kg} /$ day over the exposure period of gestational days 519. The vehicle control (VC) group was also maintained. All dams were subjected to a cesarean section on gestational day 20 and the fetuses were examined for external, visceral, and skeletal alterations.

Results: There was no significant difference found during maternal examination (body weights, food consumption, numbers of pregnant and nonpregnant female rats) or reproductive parameters (gravid uterus weights, litter size and weights, number of fetuses, sex ratio (male/female numbers of implantations and resorption, number of implantation per female, pre-and post-implantation loss (\%), dead and live fetuses (\%), numbers and weights of corpora lutea) in Fenu-FG-treated as compared to VC group. Furthermore, the few incidental and non-significant malformations were observed in Fenu-FG-treated as well as VC group during external, visceral or skeletal examinations.
\end{abstract}

Conclusion: The prenatal oral exposure of Fenu-FG during organogenesis period to pregnant female rats was devoid of maternal or developmental (fetotoxicity or teratogenicity) with "No Observed Adverse Effect Level" (NOAEL) greater than $1000 \mathrm{mg} / \mathrm{kg}$.

Keywords: Developmental toxicity, Fenugreek seeds extract, Furostanol saponin glycosides, OECD Test No. 414

(C) 2016 The Authors. Published by Innovare Academic Sciences Pvt Ltd. This is an open access article under the CC BY license (http://creativecommons.org/licenses/by/4. 0/) DOI: http://dx.doi.org/10.22159/ijpps.2016v8i12.14942

\section{INTRODUCTION}

There is a growing interest worldwide to identify novel functional foods and food supplement with biological activity with limited toxicity [1]. The natural botanical substances and derived products are being used as food supplements for their purported medical benefits [2] or as a safe and natural food grade additives for formulations [3]. These supplements may comprise the whole plant, extracts or purified components for optimum health benefits $[4,5]$, which needs extensive extraction, fractionation or purification [6]. However, the presence of unknown and diversified phytoconstituents in natural products has a risk of unknown toxicity that can harm to human health [7, 8]. Therefore, safety evaluations of natural products in their standardized form (extract or fractions) became important for their safe use.

Fenugreek (Trigonella foenum-graecum L.) seeds (Family: Fabaceae) is a popular natural resource used as an ingredient of marketed food supplements. Because of long term and safe medicinal use, fenugreek seeds derived ingredients have a generally regarded as safe (GRAS) status in the United States. Fenugreek has a long history of medical uses in Ayurvedic and Chinese medicine as a general health tonic to improve metabolism and health. The use of fenugreek seeds as a remedy for many disorders is cited in the traditional and modern literature $[9,10]$. Fenugreek seeds are also integral parts of many ayurvedic formulations [11]. The consumption of fenugreek seeds is highly recommended for many conditions for women health improvement [12] especially during lactation is highly recommended in Indian tradition $[13,14]$.

Fenugreek seeds are a rich source of a many phyto-constituents with varied biological properties. Glycosides are most notable amongst them. Feugreek seed contains a variety of furostanol [15] and flavonol [16-18] glycosides. Furostanol glycosides from fenugreek seed are reported to have anti-inflammatory [19], anti-melanogenic [19] and androgenic [20] potential. Flavonoid glycosides from fenugreek seeds are reported as anti-inflammatory, antinociceptive [21], anti-oxidant [22, 23], and lipid lowering properties [23]. Saponins are amphipathic glycosides which form a soap-like foaming when shaken in aqueous solutions in which one or more hydrophilic glycoside moieties combined with a lipophilic triterpene derivative. Saponins from a variety of natural sources are reported to exhibit a range of biological properties [24].

The furostanol saponin glycosides (FG), a major constituents from fenugreek seed, demonstrated excellent potential as a food supplement due to its biological activities [20,25-28]. The efficacy of FG-based standardized fenugreek seeds extract (Fenu-FG) as an androgenic and anabolic supplementation in male rats [20] and human subjects [25] has been reported earlier. Furthermore, double-blind, randomized, placebo-controlled studies confirmed libido enhancement properties of Fenu-FG in young and aging males $[26,27]$ and menstruating female subjects [28] with good safety profile. Considering applications of Fenu-FG as a food supplement in female subjects, evaluation of reproductive safety profile of Fenu-FG supplementation in females, especially during prenatal exposure with well-accepted international guidelines is needed.

During past preclinical studies, a crude form of fenugreek seed powder or extract was found to be safe for long-term administration $[29,30]$ even during pregnancy period $[31,32]$. However, there have been few reports of reproductive toxicity of crude extract of fenugreek seeds during prenatal exposure in rabbit [33], mice [34, 35] and rats [33, 36]. However, these reports utilized whole and crude extract with unknown composition and not standardized to any marker compounds. The safety evaluations of fenugreek seed extract standardized to specific marker compound is lacking. Recently, Prenatal developmental toxicity evaluation of low molecular weight 
galactomannans based standardized fenugreek seed extract during pregnancy period of rats has been reported [37]. However, such safety study on Fenu-FG, which as different marker compound (FG), has not yet been reported. Therefore, the present study was undertaken with the objective of safety evaluation of Fenu-FG on pregnant female rats and their fetuses during prenatal development, following oral exposure, especially during the gestation period. The well accepted international guidelines for such study is set forth by Organization for Economic Co-operation and Development (OECD) guideline, OECD. Test No. 414 [38] was followed.

\section{MATERIALS AND METHODS}

\section{Animals}

The study was conducted in accordance with the principles of Good Laboratory Practice as set forth by OECD and 'Committee for the Purpose of Control and Supervision of Experiments on Animals (CPCSEA) Guidelines for Laboratory Animal Facility'. The study protocol was approved by Institutional Animal Ethics Committee (IAEC) of INTOX Pvt Ltd, Pune, India (Approval number: 14160/14161). The nulliparous and non-pregnant Wistar female rats (aged 12 to $16 \mathrm{w}$ ) bred in-house were used for the present study. After $5 \mathrm{~d}$ of acclimatization, female rats were housed overnight with adult fertile male rats. The day on which sperms was detected in the vaginal smear was considered to be Gestational Day 0 (GD0) for that specific female rat. Mated females were singly housed in solid polypropylene cages with stainless steel grill tops and bedding of clean and sterilized paddy husk.

The pelleted feed (M/s Provimi Animal Nutrition India Pvt. Ltd., Bangalore, India) and filtered water were provided ad libitum. Animal rooms were maintained in air-conditioned rooms with 10 to 15 air changes per $\mathrm{h}$ and temperature between $22 \pm 3{ }^{\circ} \mathrm{C}$, a relative humidity of $50 \pm 20 \%$, and illumination cycle set to $12 \mathrm{~h}$ light and $12 \mathrm{~h}$ dark. After mating is confirmed (GD0), pregnant rats were randomly assigned to the vehicle control (VC) and treatment groups.

\section{Chemicals}

The test compound, Fenu-FG (standardized to $75.23 \%$ of furostanol saponin glycosides as a marker compound) was prepared and characterized by earlier reported method [20] and provided by Indus Biotech Private Limited (Pune, India). Fenu-FG is also an active component of marketed supplementation, Testofen ${ }^{\circledR}$ (Gencor Pacific Limited, Hong Kong). The solution of Fenu-FG was prepared fresh every day before dosing using analytical grade water (a vehicle). Dosage volume of $5 \mathrm{ml} / \mathrm{kg}$ body weight was maintained.

\section{Method}

The OECD Guidelines (Test No. 414:Prenatal Development Toxicity Study) was followed [38]. The main study was done after the conduct of the dose-range finding study.

\section{Dose-range finding study}

Male and Female rats (1:2 ratio) cohabited overnight. They were examined daily for the presence of spermatozoa in vaginal smear next day morning. The day on which the sperms were found in the vagina was considered gestational day 0 (GD0). On GD0, the female rats with the presence of spermatozoa in the vagina (dams) were randomized into 4 groups of seven rats each. From day 5 of gestation (GD05) GD5 to day 19 of gestation (GD19), they were administered either with vehicle (Water) or Fenu-FG $(250 \mathrm{mg} / \mathrm{kg}, 500 \mathrm{mg} / \mathrm{kg}$ or $1000 \mathrm{mg} / \mathrm{kg}$ ) respectively. These rats were checked for systemic toxicity, body weight, and food consumption. All dams were sacrificed on day 20 of gestation (GD20) and subjected to necropsy examination for ovaries and uterine contents. Fetal abnormalities by external examination were made. The dose level of $1000 \mathrm{mg} / \mathrm{kg}$ body weight (the limit dose) did not result in any remarkable maternal or fetal toxicity in the exposed rats. Therefore, the doses of $250 \mathrm{mg} / \mathrm{kg}, 500 \mathrm{mg} / \mathrm{kg}$ and $1000 \mathrm{mg} / \mathrm{kg}$ body weight were selected for the main study.

\section{Main study}

On GD0, 120 pregnant female rats were selected and randomized into 4 groups of 30 rats each. The rats were gavaged daily from GD5 to GD19 with either vehicle (G1:VC) or Fenu-FG (G2:250 mg/kg, $\mathrm{G} 3: 500 \mathrm{mg} / \mathrm{kg}$ or $\mathrm{G} 4: 1000 \mathrm{mg} / \mathrm{kg}$ ). The female rats were observed at least once daily. Starting from GD5, food consumption was measured at $3 \mathrm{~d}$ intervals. Body weights of each female dam (maternal) were recorded on GD0, GD5, GD8, GD11, GD14, GD17 and just prior to their terminal sacrifice on GD20. All rats were euthanized on GD20 by $\mathrm{CO}_{2}$ asphyxiation. The uterus from each female dams was examined for the number and placement of uterine implantation sites, the number of fetuses (live or dead), the number of resorptions (early or late) and any abnormalities of the uterus or embryonic sac, the number of corpora lutea of ovaries. Pre-implantation and postimplantation loss was calculated as follows: pre-implantations loss = [(no. of corpora lutea - no. of implantations)/no. of corpora lutea] $\times$ 100 and post-implantation loss $=[$ (no. of dead implants $) /$ no. of total implantations] $\times 100$ [39]. Fetal examination for sex (gender) and the body weight of each fetus were determined. Uteri which had no visible implantation sites were stained with ammonium sulfide $(10 \%)$ to detect very early resorptions [40].

All live fetuses were individually weighed; sex was determined and counted and examined for external anomalies in a uniform order (from head to tail) for external malformations. Live fetuses were euthanized by using diethyl ether vapors. Visceral examination of one-half of the fetuses from each litter female rat (random selection) by Wilson's Technique was performed for assessment of soft tissue development [41]. The remaining half number of the fetuses were sacrificed, eviscerated and processed for skeletal examination (Alizarin Red S staining method) [42].

\section{Statistical analysis}

The data was presented as mean \pm standard deviation (SD). Gestational body weights, body weight change, and food consumption/day, gravid uterus weight, pre-and post-implantation loss (\%), dead and live fetuses (\%) and litter weight (total, male and female) were analyzed by one-way analysis of variance, followed by Dunnett's test. Numbers of corpora lutea, implantation per female, early resorptions and late resorptions, litter size, number of fetuses (total, live and dead), sex ratio (male/female), incidences of malformations (fetal visceral and skeletal) were analyzed by using the Kruskal-Wallis test, followed by the Mann-Whitney test. Numbers of pregnant and non-pregnant female rats, the number of live and dead rats were analyzed by using Fisher's test. Treated groups were compared with respective VC group. The values were considered significance at $\mathrm{P}<0.05$.

\section{RESULTS}

\section{Maternal examination related parameters}

No treatment-related clinical signs, effects on body weight or gross pathological changes were observed in any of treatment groups during the study period except the incidental death of 2 dams in each of FenuFG (250 and $1000 \mathrm{mg} / \mathrm{kg}$ ) treated group. There was not causative pathological observations in dead dams were observed, so these observations were not treatment related. All other females in treatment groups and VC group survived to scheduled terminal sacrifice. The daily examination did not reveal any treatment-related clinical signs, in any dams, from any dose group, during the period of the study. There were no statistically significant changes in mean maternal body weights and body weight gains throughout the study (table 1). Maternal food consumption was unaffected by treatment (table 1).

\section{Reproductive parameters related to embryo-fetal examination}

There were no effects of Fenu-FG on pre-and post-implantation loss, resorptions, live fetuses, fetal sex ratio (percent male fetuses per litter), fetal body weights. There was an increase in percent postimplantation loss in the G4 $(1000 \mathrm{mg} / \mathrm{kg})$, but it was not found to be statistically significant (table 2). 
Table 1: Effects of Fenu-FG on maternal parameters during organogenesis period in pregnant female rats

\begin{tabular}{|c|c|c|c|c|}
\hline \multirow[t]{3}{*}{ Parameters } & \multirow[t]{2}{*}{ G1 } & \multicolumn{3}{|c|}{ Fenu-FG treatment } \\
\hline & & G2 & G3 & G4 \\
\hline & VC & $250 \mathrm{mg} / \mathrm{kg}$ & $500 \mathrm{mg} / \mathrm{kg}$ & $1000 \mathrm{mg} / \mathrm{kg}$ \\
\hline \multicolumn{5}{|l|}{ Pregnancy data } \\
\hline Rats per group & 30 & 30 & 30 & 30 \\
\hline $\begin{array}{l}\text { Confirmed pregnancy } \\
\text { at necropsy }\end{array}$ & 28 & 26 & 30 & 26 \\
\hline Pregnancy rate $(\%)$ & 93.3 & 86.6 & 100 & 86.6 \\
\hline \multicolumn{5}{|l|}{ Maternal data } \\
\hline Body weight (g) GD05 & $219.32 \pm 24.48$ & $213.26 \pm 16.73$ & $216.33 \pm 20.60$ & $219.65 \pm 22.99$ \\
\hline Body weight (g) GD20 & $290.32 \pm 33.22$ & $273.65 \pm 27.12$ & $277.83 \pm 34.22$ & $282.30 \pm 37.29$ \\
\hline Body weight change (g) during GD5 to GD20 & $71.0 \pm 16.6$ & $60.4 \pm 19.9$ & $61.5 \pm 19.8$ & $62.7 \pm 20.4$ \\
\hline Corrected Body weight (g) & $241.80 \pm 24.50$ & $227.00 \pm 15.20$ & $230.80 \pm 21.40$ & $237.40 \pm 23.70$ \\
\hline Food consumption (g/day) during GD5 to GD20 & $14.5 \pm 1.9$ & $13.5 \pm 2.4$ & $13.2 \pm 2.6$ & $13.7 \pm 2.1$ \\
\hline
\end{tabular}

Values are expressed as mean \pm SD. $n=30$ female rats per group were randomized. VC-Vehicle control, GD-Gestational Day.

Table 2: Effects of Fenu-FG on reproductive parameters during organogenesis period in pregnant female rats

\begin{tabular}{|c|c|c|c|c|}
\hline \multirow[t]{3}{*}{ Parameter } & \multicolumn{4}{|c|}{ Fenu-FG treatment } \\
\hline & VC & $250 \mathrm{mg} / \mathrm{kg}$ & $500 \mathrm{mg} / \mathrm{kg}$ & $1000 \mathrm{mg} / \mathrm{kg}$ \\
\hline & G1 & G2 & G3 & G4 \\
\hline All litters ${ }^{\mathrm{a}}$ & 28 & 26 & 30 & 26 \\
\hline Gravid uterus weight (g) & $48.5 \pm 14.3$ & $46.7 \pm 16.4$ & $47 \pm 17.7$ & $44.9 \pm 19.8$ \\
\hline Corpora lutea (no.) & $10.4 \pm 2.5$ & $10.2 \pm 2.2$ & $9.8 \pm 1.9$ & $9.7 \pm 3.1$ \\
\hline Total implantation per female (no.) & $9.4 \pm 2.3$ & $9.2 \pm 2.4$ & $9.2 \pm 1.8$ & $8.3 \pm 3.4$ \\
\hline Pre-implantation loss $(\%)^{c}$ & $19.1 \pm 14.50$ & $17.3 \pm 10.8$ & $13.1 \pm 15$ & $27.9 \pm 19.60$ \\
\hline Post-implantation loss $(\%)^{\mathrm{d}}$ & $26.8 \pm 25.30$ & $19 \pm 8.20$ & $38.1 \pm 33$ & $51.3 \pm 46.60$ \\
\hline Early resorptions (no.) & $1.7 \pm 1.5$ & $1.9 \pm 1.1$ & $2.6 \pm 3$ & $2.4 \pm 1.6$ \\
\hline Late resorptions (no.) & $1.0 \pm 0.0$ & - & $2.8 \pm 3.5$ & - \\
\hline Litters available for evaluation & 27 & 25 & 28 & 25 \\
\hline Litter size (no.) & $8.89 \pm 1.93$ & $8.76 \pm 2.35$ & $8.36 \pm 2.41$ & $8.08 \pm 3.19$ \\
\hline Total live foetuses (no.) & $8.85 \pm 1.99$ & $8.76 \pm 2.35$ & $8.36 \pm 2.41$ & $8.08 \pm 3.19$ \\
\hline Total dead foetuses (no.) & $0.04 \pm 0.20$ & - & - & - \\
\hline Live male foetuses (no.) & $4.44 \pm 1.63$ & $4.5 \pm 1.96$ & $4.3 \pm 1.38$ & $4.88 \pm 2.23$ \\
\hline Live female foetuses (no.) & $4.58 \pm 1.70$ & $4.25 \pm 2.01$ & $4 \pm 1.82$ & $3.54 \pm 1.84$ \\
\hline Male/female sex ratio (no.) & $1.22 \pm 0.97$ & $1.29 \pm 1.02$ & $1.15 \pm 0.68$ & $2.04 \pm 2.10$ \\
\hline Average foetal weight (g) & $3.58 \pm 0.33$ & $3.52 \pm 0.41$ & $3.82 \pm 0.58$ & $3.75 \pm 0.25$ \\
\hline Average male foetal weight (g) & $3.71 \pm 0.30$ & $3.73 \pm 0.30$ & $3.97 \pm 0.52$ & $3.81 \pm 0.33$ \\
\hline Average female foetal weight (g) & $3.5 \pm 0.29$ & $3.36 \pm 0.58$ & $3.73 \pm 0.59$ & $3.68 \pm 0.31$ \\
\hline
\end{tabular}

aFemales with confirmed pregnancy (including those died) (Nos.), bValues are expressed as means \pm standard deviation (SD), c[(Number of Corpora Lutea-Number of implantations)/Number of Corpora Lutea] $\times 100$, d[(Number of dead implants)/Total number of implantations] $\times 100$.

\section{Fetal malformations and variations}

In general, the embryo-fetal examination did not show any major abnormalities which could have caused any functional damage to these fetuses if allowed to grow in the normal course (table 3). Each fetus was externally examined for any abnormal findings with respect to length, cranium, eyes, palate, limbs, tail, genitals, sex, etc. Anasarca was observed in one fetus from VC group, and the small sized (runt) fetus was observed in G3 (500 mg/kg). In visceral examinations, hydrocephalus of lateral ventricles of the brain was observed in two fetuses from VC, three fetuses from G2 $(250 \mathrm{mg} / \mathrm{kg})$ and two fetuses from $\mathrm{G} 3(500 \mathrm{mg} / \mathrm{kg})$. Retinal folding was observed in one fetus from $\mathrm{G} 2(250 \mathrm{mg} / \mathrm{kg})$. Whole body distortion in one fetus was observed in VC group. Few incidences of fetal soft tissue abnormalities encountered in this study are all classified as either normal variants or minor anomalies and considered to be incidental and not treatment related. In skeletal examinations, as per skull anomaly is concerned, variation from the ossification patterns was seen like unossified, scrambled, poorly and incompletely ossified skulls. Such variations were observed in 14 fetuses from the VC, 6 from G2 (250 mg/kg), 20 fetuses from G3 (500 mg/kg) and 4 fetuses from G4 (1000 mg/kg) which were classified as normal variants. Six fetuses from VC, 18 from G2 (250 mg/kg) and one each from G3 $(500 \mathrm{mg} / \mathrm{kg})$ and G4 (1000 mg/kg) were observed with poor and incomplete ossifications of sternebrae. Unossified 5th and 6th sternebra were also encountered in all dose groups like 14 fetuses in VC, 21 in G2 (250 mg/kg), 8 in G3 (500 mg/kg) and one in G4 (1000 $\mathrm{mg} / \mathrm{kg}$ ). These were all classified as normal variants. Two fetuses in G3 $(500 \mathrm{mg} / \mathrm{kg})$ with poor ossification of cervical vertebrae and one fetus from G4 (1000 mg/kg) with unossified caudal vertebra was observed as normal variants.

Minor anomalies like branched, split, rudimentary, dumbbell shaped and asymmetrically shaped sternebrae were seen in all dose groups. These anomalies observed in 5 fetuses from VC, 8 fetuses from G2 (250 mg/kg), 6 from G3 (500 mg/kg) and 7 fetuses from G4 (1000 $\mathrm{mg} / \mathrm{kg}$ ). Minor anomalies in ribs like rudimentary, wavy, extra, accessory and asymmetrical ribs were observed in 3 fetuses from VC, 2 fetuses from G2 (250 mg/kg), 34 fetuses from G3 (500 mg/kg) and 7 fetuses from G4 (1000 mg/kg). Dumbbell shaped and fused vertebrae (thoracic, lumbar, sacral and caudal) were observed in 3 fetuses from VC, 9 fetuses from G3 $(500 \mathrm{mg} / \mathrm{kg})$ and one fetus from G4 (1000 mg/kg) (table 3). In general, the skeletal examination did not show any major abnormalities which could have caused any functional damage to these fetuses if allowed to grow in the normal course. The abnormalities noticed could be considered as the variations which might have occurred during development but got repaired and normalized during the normal course of development. 
Table 3: Effects of Fenu-FG on fetal malformations and variations during organogenesis period in pregnant female rats

\begin{tabular}{|c|c|c|c|c|}
\hline \multirow[t]{3}{*}{ Parameter } & \multicolumn{4}{|c|}{ Fenu-FG treatment } \\
\hline & VC & $250 \mathrm{mg} / \mathrm{kg}$ & $500 \mathrm{mg} / \mathrm{kg}$ & $1000 \mathrm{mg} / \mathrm{kg}$ \\
\hline & G1 & G2 & G3 & G4 \\
\hline \multicolumn{5}{|l|}{ Total No. Fetuses (litters) examined } \\
\hline External & 240 & 219 & 234 & 202 \\
\hline Visceral & 116 & 102 & 110 & 96 \\
\hline Skeletal & 124 & 117 & 124 & 106 \\
\hline \multicolumn{5}{|l|}{ External Malformation } \\
\hline Anasarca & 1 & 0 & 0 & 0 \\
\hline \multicolumn{5}{|l|}{ External Variations } \\
\hline Small sized fetus (runt) & 0 & 0 & 1 & 0 \\
\hline \multicolumn{5}{|l|}{ Visceral variations } \\
\hline $\begin{array}{l}\text { Brain: Hydrocephalus of } \\
\text { lateral ventricles (slight) }\end{array}$ & 2 & 3 & 2 & 0 \\
\hline Eye: Retinal folding (right) & 0 & 1 & 0 & 0 \\
\hline \multicolumn{5}{|l|}{ Skeletal variations } \\
\hline Skull ossification & 14 & 6 & 20 & 4 \\
\hline \multicolumn{5}{|l|}{ Sternebra Variations } \\
\hline Incomplete/Poor ossification & 6 & $18^{\#}$ & 1 & 1 \\
\hline Un-ossified ( $5^{\text {th }}$ and $\left.6^{\text {th }}\right)$ & 14 & $21 \#$ & 8 & 1 \\
\hline $\begin{array}{l}\text { Branched, spilt, rudimentary, } \\
\text { dumbbell and asymmetrical } \\
\text { Rib Variations }\end{array}$ & 5 & 8 & 6 & 7 \\
\hline $\begin{array}{l}\text { Rudimentary }\left(14^{\text {th }}\right) \text {, wavy, } \\
\text { asymmetrical, extra, accessory }\end{array}$ & 3 & 2 & $34{ }^{\#}$ & 7 \\
\hline \multicolumn{5}{|l|}{ Vertebrae variations } \\
\hline Cervical: Poor ossification & 0 & 0 & 2 & 0 \\
\hline Caudal: Not ossified & 0 & 0 & 0 & 1 \\
\hline Thoracic vertebra: centra dumbbell shaped & 0 & 0 & 7 & 0 \\
\hline Caudal: Fused & 1 & 0 & 0 & 0 \\
\hline Sacral: Fused & 1 & 0 & 0 & 0 \\
\hline Lumbar: Fused & 1 & 0 & 0 & 0 \\
\hline
\end{tabular}

Fetuses from pregnant female rats per group were examined. The incidence of the individual defect is presented as a number of fetuses (numbers of litters). VC-Vehicle control, \# P<0.05 as compared with VC (Mann-Whitney test).

\section{DISCUSSION}

The safety of standardized extracts of natural products cannot be assumed or directly correlated for the safety of powder, fraction or crude unstandardized extract. For example, steviol glycosides (SGs), a well-known sweetener contains a fraction of Stevia rebaudiana leaves, did not show reproductive toxicity in rats [43] whereas crude stevia leaf extracts showed adverse effects (renal and cardiovascular) as well as reduced fertility of in male and female rats [44-47]. Therefore, the safety of each food supplement needs to be ensured during prenatal exposure during pregnancy period in order to ensure safety in female users [48].

The present study evaluated the toxicity potential of oral gavage exposure of a furostanol saponin glycoside based standardized fenugreek seed extract, Fenu-FG in 30 pregnant female rats during developmental period i.e. gestational days GD5 through GD19. On day 20 of gestation, the females were sacrificed to examine ovaries, uteri, and fetuses for assessment of toxicity in terms of maternal and fetal parameters. Fenu-FG did not show any adverse effect on fetal weight or number of fetuses and their skeletal and soft tissue alterations. Furthermore, Fenu-FG showed no harmful effects on maternal as well as fetal parameters during gestational days (GD1-GD21) in rats, Intrauterine growth and survival were unaffected by Fenu-FG. In addition to the absence of treatment-related malformations, there were no significant changes in the incidence of external, visceral or skeletal variations. Taken together, these results indicated the absence of teratogenicity or abortifacient potential during oral exposure FenuFG during the gestational period. Thus, the "No-Observed-AdverseEffect-Level (NOAEL) of Fenu-FG for maternal toxicity was found to be greater than or equal to $1000 \mathrm{mg} / \mathrm{kg} /$ day.

Pregnancy rate is the proportion of mated pairs that have produced at least one pregnancy within a fixed period where pregnancy is determined by the earliest available evidence that fertilization has occurred. Our results showed no significant difference in pregnancy rate amongst the treatment groups. The G3 $(500 \mathrm{mg} / \mathrm{kg})$ showed $100 \%$ pregnancy rate as compared to $93.3 \%$ pregnancy rate shown by VC group. Significant shortening of gestation period can lead to adverse outcomes of pregnancy such as decreased birth weight and offspring survival. Significantly longer gestation may be caused by the failure of the normal mechanism for parturition and may result in death or impairment of offspring. During the present study, FenuFG did not show any adverse effect percentage of pregnancy rate and retain the normal length of gestation. There was no change in body weights, body weight gains, and food consumption of pregnant rats in tested dose levels. Similarly, fertility related parameters such as a number of early and late resorptions, litter size, and a number of fetuses did not show significant changes during our study. Increase in a number of resorptions and/or implantation loss is an indicator of litter size for the individual dam. An increase in percent postimplantation loss was observed in Fenu-FG $(1000 \mathrm{mg} / \mathrm{kg} /$ day $)$ treated group. However, such changes were statistically not significant and therefore, considered incidental

The results of present study showed no evidence of teratogenic effects was observed after oral administration of Fenu-FG up to $1000 \mathrm{mg} / \mathrm{kg} /$ day. Human equivalent dose (HED) can be derived from NOAEL by using USFDA guidance for Industry [49]. Considering NOAEL of $1000 \mathrm{mg} / \mathrm{kg}$ in pregnant female rats, HED is approximately $9.7 \mathrm{~g}$ considering (considering the average human weight of $60 \mathrm{~kg}$ ). The HED value of $9.7 \mathrm{~g}$ per day is much higher than effective efficacy dose of Fenu-FG (600 mg per day) in male volunteers $[25,27]$. This safety information during a gestational period in pregnant female rats will form an important basis for the clinical development as a safe food supplement or botanical agent for female specific applications.

\section{CONCLUSION}

The prenatal exposure of Fenu-FG (dose up to $1000 \mathrm{mg} / \mathrm{kg}$, oral) during organogenesis period to female rats did not show maternal 
or embryo-fetal toxicity and no teratogenicity. The oral dose of 1000 $\mathrm{mg} / \mathrm{kg}$, was found as the NOAEL of Fenu-FG during the gestational period in pregnant female rats.

\section{ACKNOWLEDGEMENT}

This study was performed at the Intox Private Limited, Pune, India.

\section{CONFLICT OF INTERESTS}

The study is supported by Indus Biotech Private Limited, Pune, India.

\section{REFERENCES}

1. Gazem RAA, Chandrashekariah SA. Pharmacological properties of Salvia Hispanica (Chia) seeds: a review. J Crit Rev 2016;3:63-7.

2. Abdel-Rahman A, Anyangwe N, Carlacci L, Casper S, Danam RP, Enongene $\mathrm{E}$, et al. The safety and regulation of natural products used as foods and food ingredients. Toxicol Sci 2011;123:333-48.

3. Dey P, Maiti S, Sa B. Locust bean gum and its application in pharmacy and biotechnology: an overview. Int J Curr Pharm Rev Res 2012;4:7-11.

4. Schilter B, Andersson C, Anton R, Constable A, Kleiner J, O'Brien $\mathrm{J}$, et al. Guidance for the safety assessment of botanicals and botanical preparations for use in food and food supplements. Food Chem Toxicol 2003;41:1625-49.

5. Walker R. Criteria for risk assessment of botanical food supplements. Toxicol Lett 2004;149:187-95.

6. Haschek WM, Rousseaux CG, Wallig MA. Haschek And Rousseaux's Handbook of Toxicologic Pathology. 1st ed. Amsterdam: Elsevier; 2013.

7. Palmer ME, Haller C, McKinney PE, Klein-Schwartz W, Tschirgi A, Smolinske SC, et al. Adverse events associated with dietary supplements: an observational study. Lancet 2003;361:101-6.

8. Pittler M, Ernst E. Systematic review: hepatotoxic events associated with herbal medicinal products. Aliment Pharmacol Ther 2003;18:451-71.

9. Saini D, Dhingra AK, Chopra B, Parle M. Psychopharmacological investigation of the nootropic potential of Trigonella foenum gracum linn. in mice. Asian J Pharm Clin Res 2011;4:76-84.

10. Chaudhary P, Ahmad S, Khan NA. Herbal plants-a boon for hepatotoxicity. Asian J Pharm Clin Res 2016;9:37-40.

11. Jain PK, Ak S, Das D. Alternative herbal drugs used for treating hair disease. Asian J Pharm Clin Res 2016;9:110-2.

12. Basch E, Ulbricht C, Kuo G, Szapary P, Smith M. Therapeutic applications of fenugreek. Altern Med Rev 2003;8:20-7.

13. Schaffir J, Czapla C. Survey of lactation instructors on folk traditions in breastfeeding. Breastfeed Med 2012;7:230-3.

14. Nadkarni KM. editor. The Indian materia medica. 3rd ed. Bombay: Popular Prakashan; 1994.

15. Kang LP, Zhao Y, Pang X, Yu HS, Xiong CQ, Zhang J, et al. Characterization and identification of steroidal saponins from the seeds of Trigonella foenum-graecum by ultra highperformance liquid chromatography and hybrid time-of-flight mass spectrometry. J Pharm Biomed Anal 2013;74:257-67.

16. Benayad Z, Gomez-Cordoves C, Es-Safi NE. Characterization of flavonoid glycosides from fenugreek (Trigonella foenumgraecum) crude seeds by HPLC-DAD-ESI/MS analysis. Int J Mol Sci 2014; 15:20668-85.

17. Pang X, Kang LP, Yu HS, Zhao Y, Xiong CQ, Zhang J, et al. New kaurene diterpenoid glycosides from fenugreek seeds. Nat Prod Res 2012. http://dx.doi.org/10.1080/14786419.2012.722087

18. Rayyan S, Fossen T, Andersen OM. Flavone C-glycosides from seeds of fenugreek, Trigonella foenum-graecum L. J Agric Food Chem 2010;58:7211-7.

19. Kawabata T, Cui MY, Hasegawa T, Takano F, Ohta T. Antiinflammatory and anti-melanogenic steroidal saponin glycosides from Fenugreek (Trigonella foenum-graecum L.) seeds. Planta Med 2011;77:705-10.

20. Aswar U, Bodhankar SL, Mohan V, Thakurdesai PA. Effect of furostanol glycosides from Trigonella foenum-graecum on the reproductive system of male albino rats. Phytother Res 2010;24:1482-8.

21. Mandegary A, Pournamdari M, Sharififar F, Pournourmohammadi S, Fardiar R, Shooli S. Alkaloid and flavonoid-rich fractions of fenugreek seeds (Trigonella foenum-graecum L.) with antinociceptive and anti-inflammatory effects. Food Chem Toxicol 2012;50:2503-7.

22. Kenny O, Smyth TJ, Hewage CM, Brunton NP. Antioxidant properties and quantitative UPLC-MS analysis of phenolic compounds from extracts of fenugreek (Trigonella foenumgraecum) seeds and bitter melon (Momordica charantia) fruit. Food Chem 2013;141:4295-302.

23. Belguith-Hadriche O, Bouaziz M, Jamoussi K, El Feki A, Sayadi S, Makni-Ayedi F. Lipid-lowering and antioxidant effects of an ethyl acetate extract of fenugreek seeds in high-cholesterol-fed rats. J Agric Food Chem 2010;58:2116-22.

24. Price KR, Johnson IT, Fenwick GR. The chemistry and biological significance of saponins in foods and feedingstuffs. Crit Rev Food Sci Nutr 1987;26:27-135.

25. Wankhede S, Mohan V, Thakurdesai P. Beneficial effects of fenugreek glycoside supplementation in male subjects during resistance training: a randomized controlled pilot study. J Sports Health Sci 2016;5:176-82.

26. Rao A, Steels E, Inder WJ, Abraham S, Vitetta L. Testofen, a specialized Trigonella foenum-graecum seed extract reduces age-related symptoms of androgen decrease, increases testosterone levels and improves sexual function in healthy aging males in a double-blind, randomized clinical study. Aging Male 2016;19:134-42.

27. Steels E, Rao A, Vitetta L. Physiological aspects of male libido enhanced by standardized Trigonella foenum-graecum extract and mineral formulation. Phytother Res 2011;25:1294-300.

28. Rao A, Steels E, Beccaria G, Inder WJ, Vitetta L. Influence of a specialized Trigonella foenum-graecum seed extract (Libifem), on testosterone, estradiol and sexual function in healthy menstruating women, a randomized placebo-controlled study. Phytother Res 2015;29:1123-30.

29. Narasimhamurthy K, Viswanatha S, Ramesh B. Acute and subchronic toxicity assessment of debittered fenugreek powder in the mouse and rat. Food Chem Toxicol 1999;37:831-8.

30. Muraki E, Hayashi Y, Chiba H, Tsunoda N, Kasono K. Dosedependent effects, safety and tolerability of fenugreek in dietinduced metabolic disorders in rats. Lipids Health Dis 2011;10:240.

31. Mittal N, Gopaldas T. Effect of fenugreek (Trigonella foenum graceum) seeds based on the birth outcome in albino rats. Nutr Rep Int 1986;33:362-9.

32. Mittal N, Gopaldas T. Effect of fenugreek (Trigonella foenumgraecum) seed based diets on the lactational performance in albino rats. Nutr Rep Int 1986;33:477-84.

33. Kassem A, Al-Aghbari A, Molham AH, Al-Mamary M. Evaluation of the potential antifertility effect of fenugreek seeds in male and female rabbits. Contraception 2006;73:301-6.

34. Khalki L, M'hamed SB, Bennis M, Chait A, Sokar Z. Evaluation of the developmental toxicity of the aqueous extract from Trigonella foenum-graecum (L.) in mice. J Ethnopharmacol 2010;131:321-5.

35. Khalki L, Bennis M, Sokar Z, Ba-M'hamed S. The neurobehavioral developmental effects of fenugreek seeds on prenatally exposed mice. J Ethnopharmacol 2012;139:672-7.

36. Kamal R, Yadav R, Sharma J. Efficacy of the steroidal fraction of fenugreek seed extract on fertility of male albino rats. Phytother Res 1993;7:134-8.

37. Deshpande P, Mohan V, Pore MP, Gumaste S, Thakurdesai PA. Prenatal developmental toxicity evaluation of low molecular weight galactomannans based standardized fenugreek seed extract during organogenesis period of pregnancy in rats. Int J Pharm Pharm Sci 2016;8:248-53.

38. OECD. Prenatal Development Toxicity Study. OECD Guidelines for the Testing of Chemicals, Section 4:Health Effects. Paris: OECD Publishing; 2001. p. 414.

39. Burdan F, Szumiło J, Dudka J, Klepacz R, Błaszczak M, Solecki M, et al. Morphological studies in modern teratological investigations. Folia Morphol (Praha) 2005;64:1-8.

40. Salewski E. Färbemethode zum makroskopischen Nachweis von Implantationsstellen am Uterus der ratte. Naunyn Schmiedebergs Arch Pharmacol 1964;247:367.

41. Monie IW, Kho KG, Morgan J. Dissection procedures for rat foetuses permitting alizarin red staining of the skeleton and histological study of viscera. Supplement to Teratology 
Workshop Manual at Berkeley, California. Washington, D. C.: Pharmaceutical Manufacturers Association; 1965. p. 163-73.

42. Taylor P. Practical Teratology. London: Academic Press; 1986

43. Curry LL, Roberts A, Brown N. Rebaudioside a: two-generation reproductive toxicity study in rats. Food Chem Toxicol 2008;46:S21-S30.

44. Planas GM, Kuć J. Contraceptive properties of Stevia rebaudiana. Science 1968;162:1007.

45. Melis MS. Effects of chronic administration of Stevia rebaudiana on fertility in rats. J Ethnopharmacol 1999;67:157-61.

46. Melis MS. Chronic administration of aqueous extract of Stevia rebaudiana in rats: renal effects. J Ethnopharmacol 1995;47:129-34.

47. Melis MS. A crude extract of Stevia rebaudiana increases the renal plasma flow of normal and hypertensive rats. Braz J Med Biol Res 1996;29:669-75.
48. Picciano MF, McGuire MK. Use of dietary supplements by pregnant and lactating women in North America. Am J Clin Nutr 2009;89:663S-7S

49. Center for Drug Evaluation and Research. Guidance for Industry: Estimating the maximum safe starting dose in initial clinical trials for therapeutics in healthy adult volunteers. In: US Department of Health and Human Services, editor.: US Food and Drug Administration; 2005.

\section{How to cite this article}

- $\quad$ Pallavi Deshpande, Vishwaraman Mohan, Mukul Pore, Shailesh Gumaste, Prasad Thakurdesai. Prenatal developmental toxicity evaluation of furostanol saponin glycoside based standardized fenugreek seed extract during organogenesis period of pregnancy in rats. Int J Pharm Pharm Sci 2016;8(12):124-129. 